\title{
Spatial and temporal boundedness in English motion events
}

\author{
BERT CAPPELLE AND RENAAT DECLERCK
}

Shortened title:

\section{Boundedness in English motion events}

K.U. Leuven Campus Kortrijk, Belgium http://www.kuleuven.ac.be/ http://www.kulak.ac.be/

Kulak Faculty of Arts

Etienne Sabbelaan 53

B-8500 Kortrijk

bert.cappelle@kulak.ac.be renaat.declerck@kulak.ac.be

(A short biography of both authors is to be found at the end of the text.) 


\begin{abstract}
This study examines how reference to spatial boundaries can make speakers of English represent or understand a motion event as temporally bounded. Spatial boundaries can be implied by (a) the path expressed by a directional item, (b) the so-called "landmark" (Langacker, 1987) serving as 'support' for the path, and (c) the moving entity. Importantly, one and the same entity in the real world can also be conceptualized as either primarily delimited (bounded) or extended (nonbounded).

After setting the stage with an example (section 1) and dealing with some important terminological preliminaries (section 2), we take a closer look at the concept of boundaries (section 3). We then set up a four-way classification of directional prepositions in English (section 4), based on whether they refer to a path that is extended and, if so, on whether that path is specified or not for having or lacking an endboundary.

In the subsequent sections (5-7), we zoom in on the aspectual role played by adverbial particles, on the possible influence of the object NP of directional prepositions, and briefly on the role played by the NP referring to the moving entity.

The most important findings of this study are summarized in section 8 .
\end{abstract}

Keywords: Event structure; Motion events; Boundedness and telicity; Prepositions; Particles; Conceptualization

\title{
1. Introduction ${ }^{1}$
}

It is a well-known fact that words and phrases with an essentially spatial meaning can sometimes also be used to express tense-related or aspectual notions. The way going to has acquired a future tense meaning or $u p$ has become an aspectual marker are oft-cited examples. However, this does not necessarily mean that the literal use of spatial items is completely void of tense-related or aspectual information. Claims to the contrary have sometimes been made in the literature. For example, Diensberg (1990: 190) and Giddings (2001) hold that particles that are used to express a direction (e.g. down in I fell down) do not change the aspectual value of the motion event referred to by the verb. In this article, we want to show that directional phrases do have an influence on the way a motion event is conceptualized as unfolding in time.

In particular, we will be concerned with spatial boundaries that may or may not be expressed by either a directional PP or a directional particle and how these affect the temporal boundedness of a motion event. As we shall see shortly, 'temporal boundedness', or 'boundedness' for short, is an aspectual notion, which has to do with whether or not an event is represented as coming to an end. The bounding effect of spatial boundaries is illustrated by the following sentences:

(1) a. You'll have to walk through thick forest. (nonbounded motion event)

b. You'll have to walk through the thick forest. (bounded or nonbounded motion event)

c. You'll have to walk through. (bounded motion event)

In (1a), the object of the preposition through is the mass NP thick forest. Such mass NPs refer to entities without clear spatial boundaries. As a result, the event of walking through thick forest does not have a natural endpoint. For lack of such an endpoint (or other bounding elements that we do not consider here), this event remains temporally 
nonbounded. In (1b), forest is used as a count noun and the use of the implies that the entity referred to has well-defined spatial boundaries. Consequently, the event of walking through the forest is thought of as having a natural endpoint (point of completion). If the speaker instructs the hearer to reach this endpoint, the event is meant to be interpreted as temporally bounded. Alternatively, we may think of the forest as something that one can penetrate at one side and that one can get deeper and deeper into without necessarily reaching the other side. The speaker may in other words force the hearer to venture into the forest, possibly never to come out of it again. In this case, the boundaries of the forest are out of focus and the event of walking through the forest is meant to be interpreted as nonbounded. In (1c), finally, through is used as an adverbial particle. ${ }^{2}$ Interestingly, this use allows of one reading only, namely that in which an implied object with spatial boundaries is entered at one side and is exited at the other. This conceptualization (together with the use of a simple verb form) results in temporal boundedness of the motion event.

\section{Terminological preliminaries: (motion) event, moving entity, path, (non)boundedness}

It is necessary to make clear at the outset what we mean by 'events', by 'motion events', including the notions 'moving entity' and 'path', and by (temporal) '(non)boundedness'. To avoid confusion, we will not use the term boundedness in a spatial sense. When we have spatial boundedness in mind, we will refer to the quality of having boundaries instead. (The concept of 'boundaries', which we reserve for spatial boundaries, will be explained in the following section.)

'EVENTS' are to be understood here in their broadest sense, that is, not as opposed to 'states' (e.g. Gabbay and Moravcsik, 1980) or as opposed to 'processes' and 'states' (e.g. Mourelatos, 1981), but as a cover term for all four aspectual types proposed by Vendler (1967) and developed, inter alia, by Dowty (1979): states, activities, accomplishments and achievements. The reason why 'event' is preferred to the equally general and in fact less ambiguous term 'situation' is that this latter term does not form a standard collocation with 'motion'. In everyday usage, 'situation' evokes the idea of something nondynamic, which is quite at odds with the dynamicity inherent in motion events. Indeed, there are no motion events that can be classified as states. On the other hand, states can sometimes involve a typical motion expression when the conceptualizer thinks of the path that leads to a certain location (e.g. Her office is through/along this corridor). In this study, such cases of 'fictive' or 'subjective' motion (cp. Langacker, 1990; 1999; Matsumoto, 1996; Talmy, 1996) will not be counted as expressions of 'motion events' proper, but they will nonetheless be invoked to illuminate a rather important distinction that is to be made between prepositional phrases.

'MOTION EVENTS', in the present study, are those events which involve physical (rather than mental) translocation of a moving entity. By translocation we mean that the moving entity does not move 'on the spot' (e.g. as is the case when someone merely swings his arms) but moves from one place to another. In other words, 'motion' is short here for what some linguists refer to more explicitly as 'directed motion'.

In some cases, there may be more than one moving entity, as in Jill ran after Bill or John followed Mary into the room. When we talk about the moving entity, we only have the subject referent of an intransitive clause or the object referent of a transitive clause in mind, for example, John in John walked away or the cat in I threw the cat out the win- 
dow. ${ }^{3}$ Note, furthermore, that these subject or object NPs can have singular or plural reference, as in \{Jack / Jack and Jill\} ran up the hill. However, in the theoretical discussion below we will generally speak of the moving entity, keeping in mind that 'MOVING ENTITY' is a mental construct and may exhibit composite or complex structure. (We will come back to this in section 7.)

In all languages, motion events involve the conceptualization of a 'PATH', which is best thought of as a purely spatial entity: a trajectory over which motion takes place. Our definition of 'path' is thus much simpler than 'Path' in the writings of some cognitive linguists (e.g. Johnson, 1987; Casad, 1993; Ekberg, 2001), who treat it as an imageschematic concept involving force itself. Our 'path' is not imbued with energy; it is just a geometrical shape. Most paths can be thought of as a one-dimensional entity, whether it be a straight or a curved line. ${ }^{4}$ Apart from a path, motion events also involve a time period during which motion takes place, and it is quite obvious that the further the moving entity proceeds along the path, the more time goes by. So, the amount of path involved in the motion correlates with the amount of time taken up by the motion event. However, we follow Jackendoff (1983: 169; 1996: 317, n. 13) in not letting the concept of 'path' itself be partly spatial and partly temporal, as some linguists do (e.g. Miller and JohnsonLaird, 1976; Hinrichs, 1985; Verkuyl, 1993).

In English, a path can be coded or hinted at in one of three ways: (a) it can be expressed by means of a prepositional phrase (PP) or an adverbial particle specifying the path's shape, direction, starting point or endpoint; (b) it can be referred to as a measure phrase specifying the path's length; and (c) it can be incorporated into the verb. These three possibilities are illustrated in (2a), (2b) and (2c), respectively:

(2) a. They walked \{around (the city) / down (the hill) / through (the forest) / to school / back .

b. They ran \{five kilometers / two laps / a marathon .

c. They \{entered (the church) / left (the room) / crossed (the border) / climbed (the mountain) / approached (the finish) / surrounded the building / penetrated the forest $\}$.

A path-incorporating verb can be paraphrased by means of a PP. For example, along the lines of Gruber (1976) and Jackendoff $(1983 ; 1990 ; 1996)$, we can paraphrase enter (NP) as 'go in(to NP)' or climb (NP) as 'go up (NP)'.

As can be seen from the examples in (2a-c), a path is not usually expressed directly; typically, only one or a few of its aspects are coded explicitly (e.g. its shape, endpoint, length, etc.). In other words, such expressions only presuppose a path. Of course, the path need not be expressed overtly or even referred to indirectly if doing so would be irrelevant to the message conveyed. But even when no (aspect of a) path is explicitly coded in a motion event, the existence of a path is understood, since a path is an indispensable element in the ontology of all motion events (as defined above). Take, for instance, sentences like (3a) and (3b):

(3) a. They ran and ran.

b. They pushed the cart.

Both these events presuppose the existence of some path over which the event of running or of pushing the cart occurred..$^{5}$ 
Of all the sentences in English that refer to a motion event and in which (an aspect of) the path is expressed overtly, those with a directional PP or an adverbial particle undoubtedly constitute the largest group. Accordingly, this study is primarily concerned with sentences such as those given in (2a).

Having briefly explained what we mean by 'event', 'motion event', 'moving entity' and 'path', we now turn to '(NON)BOUNDEDNESS', a notion which will require more space to define and to delineate from other notions.

Nonboundedness has to do with two possible ways of representing or interpreting a particular instance of actualization of an event. An event is (represented as) bounded if the clause describing it represents the event as reaching a terminal point, i.e. as coming to an end. Otherwise it is nonbounded.

(Non)boundedness bears some resemblance to (a)telicity, and indeed in Declerck (1979) no distinction was made between these notions. For example, the test which we will use for boundedness vs. nonboundedness hinges on the (in)compatibility with ' $i n / f o r$ $\mathrm{X}$ time' durational adverbials, and ever since Garey (1957), this test is also a classic one for telicity vs. atelicity. ${ }^{6}$ It is essential, however, to recognize the distinction between (non)boundedness and (a)telicity proposed in more recent writings by Declerck (1989, 1997: 191-95) and Depraetere (1995) and adopted by Vanden Wyngaerd (2001):

(4) telic events are those that possess an inherent end point, but these are not necessarily temporally bounded, such as when the end point is not reached at all, or when the end point is reached many times over. In such cases, the events are telic but nonbounded. ${ }^{7}$

(Vanden Wyngaerd, 2001: 76)

One of the consequences of distinguishing between (non)boundedness and (a)telicity is that the use of the progressive form of a telic predicate (e.g. Mary was drawing a circle) does not impose an atelic reading on an event, as is often assumed, but has the effect of turning the event into a nonbounded one while leaving its telicity unaffected. Both the term (a)telic and the term (non)bounded are often applied to events, but it should be clear that, in our account, (a)telic event is short for 'event represented as (a)telic by a nonfinite VP, i.e. by the complemented verb without inflectional endings or auxiliaries' and that (non)bounded event is short for 'event whose actualization is represented as bounded by a finite clause'. ${ }^{8}$ Strictly speaking, since the terms (a)telicity and (non)boundedness apply to different linguistic entities, one should explicitly speak of an '(a)telic VP' (e.g. cross the street), on the one hand, and of an '(non)bounded clause' (e.g. John was crossing the street), on the other. ${ }^{9}$ We will use event in the remainder of this text, but the reader should be aware that, in the case of (non)boundedness, event means 'particular instance of an actualization, as referred to by the clause, of the kind of event denoted by the Vbar'. ${ }^{10}$ Although the distinction between (a)telicity and (non)boundedness is, in our opinion, rather important, the influence of directional phrases on (non)boundedness cannot be dissociated from their influence on (a)telicity. Directional phrases belong to the VP, and so have a direct bearing on the (a)telicity of the kind of event expressed by that VP; the (a)telicity of the VP is in turn an important determinant of the (non)boundedness of the clause.

(Non)boundedness is also to be distinguished from (im)perfectivity, which has to do with whether an event is viewed as a whole or whether it is viewed from within, as it were. English makes this distinction by means of simple versus progressive verb forms, the former expressing perfective, the latter imperfective aspect. (Im)perfectivity cross- 
cuts (non)boundedness. That is, sentences that make use of a simple verb form can be either temporally bounded (e.g. Barney drank a glass of beer) or temporally nonbounded (e.g. Barney drank beer). And although a progressive verb form typically triggers temporal nonboundedness (e.g. It is raining), it can exceptionally be used in a bounded sentence (e.g. It has been raining: the cobbles are still wet).

To summarize the last few paragraphs, we have made a threefold aspectual distinction: (non)boundedness, (a)telicity, and (im)perfectivity.

(i) (Non)boundedness is a matter of how a particular actualization of a (kind of) event is represented with respect to the question: Does the event come to an end or not?

(ii) (A)telicity is a matter of whether or not we conceptualize a kind of event as having an inherent or intended endpoint (point of completion).

(iii) (Im)perfectivity is a matter of whether or not we view a particular event as a whole and is grammatically expressed in English by the use of simple (nonprogressive) versus progressive verb forms.

Incidentally, the notion of boundedness proposed here is to be distinguished from Langacker's (2002: 87-90) notion of boundedness. Langacker makes a distinction between what he calls "perfective processes" and "imperfective processes", the former comprising Vendler's (1967) categories "activities", "achievements" and "accomplishments", the latter corresponding to Vendler's "states" (i.e. situations involving verbs like resemble, have, know, want, like, etc.). "Perfective processes", and only those, are "bounded" in his terminology, meaning essentially that they have finite duration and that their beginning and endpoint are both envisaged in the reference of the clause. "Imperfective processes" last forever, or, at least, they are conceptualized as having no beginning or end. To see the difference between our and Langacker's conception of boundedness, consider the following example:

Joan walked along the beach.

The event of walking along the beach does not have an inherent endpoint, nor is the event portrayed as coming to an arbitrary end by the clause it is used in. Therefore, it is nonbounded according to our definition of this term. (The use of the past tense does suggest that the event has come to an end, but this interpretation of boundedness is only implicated, not coded explicitly. See footnote 15.) By contrast, since the event of walking along the beach is not a state-note that it can occur in the progressive: Joan was walking along the beach - it is a perfective and hence a bounded process in Langacker's terms. In fact, our treatment of (5) shows two differences with Langacker's: while (5) in our account does not represent the event of walking along the beach as coming to an end, let alone to its (inherent) end (which it lacks, being atelic), the very same event in Langacker's account (being not a state and therefore having limited duration) does have an endpoint of its own, which is moreover fully included within the time segment designated by the clause. ${ }^{12}$

While we will not go into the manifold linguistic applications of 'temporal boundedness', the reader may well realize that a notion that is concerned with whether events are represented as reaching an endpoint or as possibly going on indefinitely is an aspectually rather important one. Boundedness is not just a theoretical concept but has been argued to be of importance, among other things, for the distribution of foregrounded versus backgrounded events in narration, for the use of tenses in subclauses, and for the use of quantified numerals with progressives (Depraetere, 2000b). 
The importance of boundedness may actually go beyond linguistics. Take the domain of Artificial Intelligence and human-machine interaction. If we instruct a robot to "go through", the system should be programmed in such a way that the robot knows it has to go all the way through a salient penetrable object. In other words, as long as the robot is still going through this implied object, it has not satisfied the command yet. By contrast, if it is instructed, say, to "go through the colon and remove mucosa", the system should be able to ask for clarification: does the robot have to go all the way through the colon or only partway? (And because of the ambiguity of and, it should also ask whether the robot has to remove mucosa only after it has gone all the way through the colon, or whether it has to remove mucosa while going (all the way or partway) through it.) Although this is a purely fictitious example, it should be clear that it can be of vital importance to know whether an event is meant to be understood as bounded or as nonbounded.

\section{The concept of boundaries}

Now that we have made clear what we understand by 'event', 'motion event', 'path', and 'temporal (non)boundedness', it is time to say something about the concept of 'boundaries'. In the case of motion events, this concept is quite straightforwardly applied to paths. As two very simple examples, consider the following sentences:

(6) a. Jules swam across the Channel.

b. Ella walked along the beach.

In (6a), the event of Jules swimming across the Channel involves crossing an endboundary, which in this case is one of the lines dividing the North Sea from the land on either side of it. In fact, both these lines are crossed: one of them at the beginning of the event, and the other at the end. ${ }^{13}$ This clause contains a telic event (because there is a conceptualization of an end-boundary to be crossed) and is bounded (because the idea imposed by the nonprogressive verb form is that the boundaries have been crossed); hence the possibility to add an inclusive adverbial like in fifteen hours. ${ }^{14}$ In (6b), the event of Ella walking along the beach does not involve crossing any boundaries. Because of that, this motion event is atelic. Since, moreover, this motion event is not linguistically represented as otherwise coming to an end in this example, the clause is nonbounded; hence the possibility to add an adverbial like for an hour or so. Evidently, the endboundary in (6a) plays a part both on the level of telicity and on the level of boundedness: firstly, the reference to an end-boundary to be crossed causes us to conceive of swimming across the Channel as a telic kind of event; secondly, in a finite clause with a simple (i.e. nonprogressive) tense form, there is automatically reference to actually crossing this end-boundary (whether in the actual or in a possible, e.g. future, world), in other words, the event is then represented as reaching its inherent endpoint, and is thus bounded. ${ }^{15}$

Not just the path has boundaries. It should be remembered that a path, as a geometrical object, is only a virtual entity in the actual world, in the sense that it cannot be seen or touched. A path exists by virtue of something that 'supports' it, that is, the more tangible surroundings that the moving entity moves over, through, across or along: the Channel, and the beach in (6a-b), for example. This 'support' too (called "landmark" in Langacker's Cognitive Grammar) can be referred to in terms of boundaries that can have a bounding effect on the motion event, as we will see. The Channel and the beach differ with 
respect to the ease with which their relevant extensions (width and length, respectively) are conceptualized as having clear and salient boundaries.

Furthermore, the moving entity can also be represented as having definite or less definite boundaries. It has long been recognized that the count-mass distinction and the definite-indefinite plural distinction have a bearing on an event's aspectuality-consider, for example, the bounding or nonbounding effect of the object NP in Barney drank a glass of beer / ten glasses of beer / beer / countless glasses of beer\}. Motion events are no less susceptible to these distinctions. Consider, for example, the effect of the subject noun phrase in $\{$ A car / Traffic / Twenty cars / Lots of cars $\}$ drove by. Notice, though, that the object NP also plays a role on the level of (a)telicity, since it is part of the VP (V-bar), whereas the subject NP only plays a role on the level of (non)boundedness.

The kinds of boundaries mentioned so far (those in the path, those in the path's "support", and those in the moving entity) will be discussed in more detail in sections 5, 6, and 7, respectively, with an emphasis on the first two kinds. There are two more sorts of boundaries that have a bearing on the temporal (non)boundedness of events. Although these boundaries are not spatial, we want to mention them briefly.

First, the time span expressed by a duration adverbial may also be conceptualized as having boundaries. Again, the definiteness of the NP referring to the time span is the determining factor in whether or not the adverbial has a bounding effect. So, for example, the duration adverbial for an hour (or for three hours) indicates a period of definite length, and therefore imposes an end-boundary on the event. This also means that while the clause Ella walked along the beach is nonbounded, the clause Ella walked along the beach for an hour no longer is, because of the bounding effect of for an hour. By contrast, the duration adverbial for hours does not specify any definite temporal boundaries, and accordingly does not have a bounding effect. In other words, it should be realized that the 'in/for $\mathrm{X}$ time' adverbial test diagnoses the (non)boundedness of the clause without the adverbial.

Secondly, the time of utterance (i.e. moment of speech) also functions, quite straightforwardly, as a boundary: it is the 'now' of the present, separating the past from the future. Because of this, an event that is represented as being situated, through the use of a past-tense form, in the past will often be understood as belonging to the past, that is, as having come to an end before the time of utterance. For example, Ella walked along the beach will normally, i.e. in the absence of an indication to the contrary (see footnote $15)$, be interpreted as having come to an end, even though the event itself does not refer to a (physical) boundary being reached or crossed. In other words, a sentence can be semantically nonbounded but pragmatically bounded. This complication can also arise if a future-tense form is used. For example, the sentence Otto will be at home when you get there may suggest that Otto is not at home at the time of utterance, but this is only an implicature, which can be cancelled (e.g. Otto will be at home when you get there. In fact, he's no doubt already in now).

Although this study is concerned with motion events in English only, the concept of 'boundaries' is one that is not particular to the English language. Indeed, it can be defined, as we have done, in nonlinguistic (i.e., physical, or possibly cognitive) terms. However, languages may differ in the sorts of items, grammatical and lexical, that interact to determine (non)boundedness. 


\section{Four sorts of directional items in English}

In this section, we will propose a classification of directional items into four more or less distinct classes. Linguists have often downplayed the difference between full PPs and particles (e.g. Klima, 1965; Emonds, 1970: 15; 1972: 546-55; Jackendoff, 1973: 345; Cowper, 1992: 24, to give but a few references). The view that adverbial particles only substantially differ from 'real' prepositions in their lack of a complement NP, and that they may therefore be called "intransitive prepositions", seems to have become a commonplace, witness for example the observation that it can be found in Huddleston and Pullum's (2002: 272) reference grammar of English. However, as we have already shown in our discussion of (1), the use of a full PP instead of a particle may alter the (a)telicity of the VP and, concomitantly, the (non)boundedness of the clause. For expository reasons, we will nonetheless disregard for now this possible difference between full PPs and particles and treat particles and 'real' prepositions together as a single group. (But we will come back to the potential difference in the following section.) In order to avoid using the cumbersome 'preposition or particle' as cover-term all the time, we propose the abbreviation ' $\mathrm{P} / \mathrm{rt}$ ', partly inspired by the informal convention to abbreviate 'he or she' as 's/he'. So, 'P/rt' stands for a word that is either a 'true' ("transitive") preposition or an adverbial particle ("intransitive preposition"). ${ }^{16}$

A first distinction among directional $\mathrm{P} / \mathrm{rt}$ 's can be made on the basis of whether or not they evoke the idea of a continuous sequence of locations. If they do, as in John walked through the garden, we are dealing with 'extended path' P/rt's; if they do not, as in John went into the room, we are dealing with 'nonextended path' P/rt's. The path these latter Prt's describe has as good as no extension. That is, they evoke a transition from one place into another with nothing in between. For example, if you get aboard a ship, there is no (or hardly a) location that might characterize you as being 'halfway on board the ship'. It's a matter of all-or-nothing: either you are aboard or you are not. Similarly, if, say, a stick comes apart in the middle, there is no intermediate location at which its two halves can be between their togetherness and their separation. This means that the motion event in these cases is conceived of as punctual (nondurative). Compare these events with the events of walking towards or around a town, in which the change of location is not instantaneous but durative and smooth, like the arrows of an analogue watch. In fact, the sense of directionality of this second class of P/rt's may be acquired only in motion constructions, since they are actually basically locative in meaning. ${ }^{17,}{ }^{18}$ The only exceptions are from, into and onto, which are true directionals and not just "locatives-gonedirectional". Indeed, they fail to be used in stative constructions (e.g. *She stood from me; *It's warm into the house; *There is a book onto the table). This said, it is quite obvious that into and onto historically derive from directional to plus locative in/on. As to from, it could be doubted whether its meaning is really binary. In $A$ ran from $B$, the actual transition from 'A being at/with B' to 'A and B being separated' is abrupt, but it could also be argued that from denotes a nonbounded path which has B as definite source-point and which has no definite endpoint.

Among 'extended path' $\mathrm{P} / \mathrm{rt}$ 's, we can make a second distinction according to whether the path is specified or not for having or lacking an end-boundary. The first subgroup falls into two classes: one referring to paths that have a definite end-boundary and one referring to paths that lack one. These classes correspond to Jackendoff's $(1990 ; 1996)$ items specifying a "bounded" path and those specifying an "unbounded" path, respectively. ${ }^{19}$ For example, to specifies a definite end-boundary while towards does not. The second subgroup contains extended path expressions that are neutral with respect to this 
distinction. It is the context which makes it clear whether they should be interpreted as implying a definite end-boundary or not:

(7) ... you may be better off walking up the hill a bit but not going up all the way... $(\mathrm{www})$

In this example, the first occurrence of up does not refer to a path with a definite endboundary but the second occurrence does.

Figure 1 lists the most common directional P/rt's in English in one or more of the four classes we distinguish. The correct classification may be debatable for some individual $\mathrm{P} / \mathrm{rt}$ 's, but we think there is some justification for the overall taxonomy presented. ${ }^{20}$ As we will see below, the membership of a P/rt to one class rather than to another is a determining factor for the temporal (non)boundedness of motion events in which they express the path. Indeed, it is the distribution of 'in/for X time' adverbials that has led to the classification given in figure 1. Of course, this distribution cannot be claimed to justify our classification, since that would make our reasoning circular. However, it can also be established on independent grounds that $\mathrm{P} / \mathrm{rt}$ 's belonging to one class are quite different from those belonging to another.

First of all, there is a difference between extended path $\mathrm{P} / \mathrm{rt}$ 's on the one hand and nonextended path P/rt's on the other. An item from the former class can often be used either as a particle or as a homophonous preposition, as in (8), while an item from the latter class typically has one use only: it is either a particle (without corresponding use as preposition) or a preposition (without corresponding use as particle), as in (9):

(8) a. Jake ran $\{$ across / across the street $\}$.

b. Jack strolled \{about / about the place\}.

c. A plane flew \{over/over us $\}$.

d. The thieves did a runner but John ran \{after/after them\}.

e. Joan climbed $\{$ up / up the mountain $\}$.

f. The limo drove slowly \{by / by the crowd $\}$.

(9) a. Joe walked $\left\{\right.$ back / *back his house . $^{21}$

b. Joy walked $\{$ away / *away the house $\}$.

c. The pieces were put $\{$ together $/ *$ together each other $\}$.

d. The cat jumped $\{*$ onto / onto the table $\}$.

e. Why did she run $\{*$ from / from me $\}$ ?

f. Why did she throw a stone $\{*$ at $/$ at me $\}$ ? 


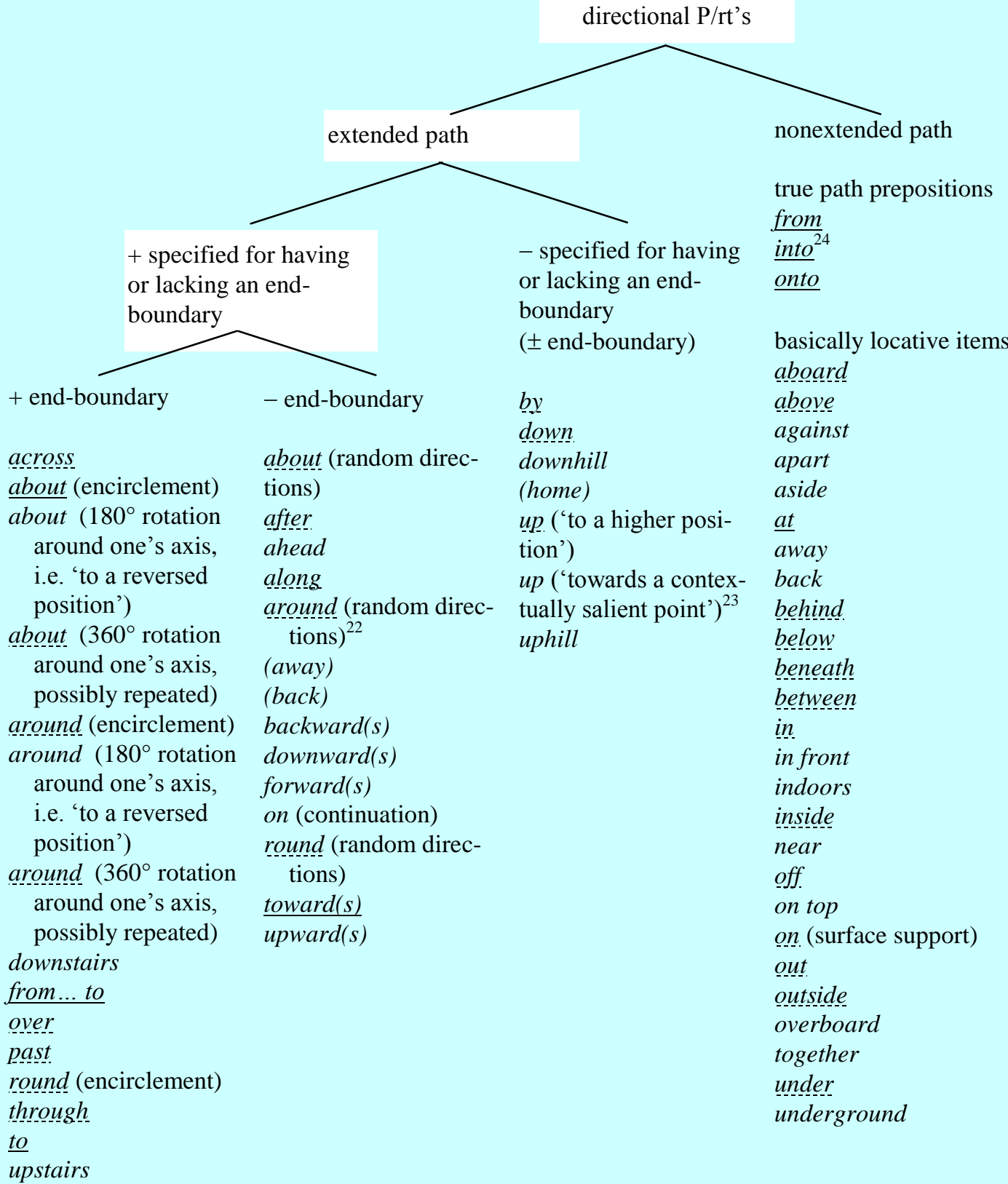

Figure 1. A four-way classification of directional P/rt's in English

(Items without underlining only occur as particles. Items with broken underlining can be used either as a particle or as a preposition . Fully underlined items only occur as prepositions.)

This difference, though, cannot serve as a watertight syntactic test to distinguish extended path directionals from nonextended path directionals. First of all, extended path $\mathrm{P} / \mathrm{rt}$ 's ending in -ward(s), -hill or -stairs can be used as particles but not as prepositions (in the latter two cases for the obvious reason that an object is already incorporated in the particle), while the extended path $\mathrm{P} / \mathrm{rt}$ to can be used as a preposition but not as a particle, except in semantically specialized verb-particle idioms like come to ('regain consciousness'). Secondly, quite a few nonextended path directionals do occur both as par- 
ticles and as prepositions: aboard, above, behind, below, beneath, between, in, inside, off, on, out, outside and under. However, we observe that most of these alternating items, when taking an NP complement, can make use of the ancillary preposition of so as to form a particle-preposition complex. For example, it is much more natural to say She walked out of the house than She walked out the house. Apart from out of, we also find off of, inside of and outside of, and even aboard of, above of, behind of, below of, and beneath of, which are not normally attested in grammars or dictionaries but do occasionally occur, though there may be a great deal of variation between dialects or even individual speakers as to the acceptability of these combinations with of. ${ }^{25}$ Here are some authentic examples, containing both locative and directional uses:

(10) a. Newton's laws which describe how moving bodies behave are adequate for explaining how apples fall off of trees but break down when dealing with the very small and very odd world of atoms and molecules. (Cobuild)

b. She had come closer than anyone in the biz, had looked inside of him and seen stuff worth redeeming. (Cobuild)

c. Of course, many attribute the outcome of the Rodney King case to the fact that the trial was moved outside of Los Angeles to Simi Valley. (Cobuild)

d. Advanced satellite positioning system (GPS) and navigation systems aboard of the aircraft. (www)

e. The leak started at the UNB Heating plant, which is located just above of the UNB campus. (www)

f. I've had lots of narrow escapes. I've had shells drop behind of me, in front of me and sideways as I've been taking a message. (www)

g. A guide to preparing written evidence for the Health Committee is below of this page. (www)

h. (...) this captures the meaning of the term 'subliminal', where 'sub-' means beneath of. (www)

It looks as if speakers of English use the ancillary preposition of after these basically locative particles as a device to maintain the particles. In other words, it could be argued that the complementing load of these items is shifted onto the preposition of, in the same way as back does not select for an NP directly but relies on the preposition to:

(11) a. [ $\quad \mathrm{Prt}_{\mathrm{rt}}$ beneath $]\left[\mathrm{PP}[\mathrm{P}\right.$ of $]\left[\mathrm{NP}_{\mathrm{NP}}\right.$ the surface $\left.]\right]$

b. $\quad\left[\mathrm{Prt}_{\mathrm{Pt}}\right.$ back $][\mathrm{PP}[\mathrm{P}$ to $][\mathrm{NP}$ his house $]]$

(Possibly, the PP in both examples may well be considered as complement of the preceding item. The crucial point is that back and beneath do not directly take an NP complement and are therefore particles. As particles, however, they may select for a PP complement.) ${ }^{26}$

It is in this respect interesting, but not altogether surprising, that some speakers, especially speakers of American English, prefer to say Max threw Felix out the window rather than ...out of the window. The NP the window does not refer to a container that locates the entity's original position (as the house would in ...out of the house) but specifies a salient portion of the landmark of an extended path: the moving entity goes out via the window. As we have seen, a path is usually not referred to in its entirety. In this case, the path traveled by the cat is more extended than the width of a window (ledge). Not being a basically locative but a true directional item in this example, out resembles other ex- 
tended-path expressions in that it readily allows the intransitive/transitive alternation, without ancillary of. ${ }^{27}$

There is also an independent motivation for distinguishing between prepositions referring to an extended path with an end-boundary and those referring to an extended path without an end-boundary. This becomes clear if we use these path expressions in sentences referring to "fictive" or "subjective" motion (cp. Bennett, 1975: 35-36; Langacker, 1990: 149-163; 1999; Matsumoto, 1996; Talmy, 1996). Here are some examples of such sentences:

(12) a. The fountain is located past the archway.

b. The only clean toilet is upstairs.

c. The entrance is to the back of the building.

d. You'll find her office through this corridor.

e. He can be found somewhere over this mountain.

(13) a. There is an observation post located downwards.

b. You may soon meet another obstacle ahead.

c. The entrance is towards the back of the building.

d. You'll find her office along this corridor.

e. He can be found somewhere about that farm.

Sentences like these do not refer to actual motion events; rather they all refer to an entity's location. Still, these locations are specified by means of a path expression, which directs the hearer's thought or vision along a path that could be followed in order to reach this location. In other words, the paths do not track the "real" (in the literature variously referred to as "factive", "objective", or "physical") motion of a moving entity but the imagined (or "virtual", "fictive", "subjective", "abstract") motion of a conceptualizer. The important observation to be made, now, is that only the sentences in (12) express the idea that the conceptualizer has to travel an imagined path that extends along the entire (salient part of the) landmark in order to reach something, which is located at the end (or even behind) this path. In other words, the sentences in (12) have what has been termed 'endpoint focus' (see, among others, Lakoff, 1987: 422; Ekberg, 2001), but those in (13) do not. This can be ascertained if we paraphrase the above sentences with the help of the phrase "all the way" versus "on the way":

(14) a. The fountain is located \{all the way / *on the way $\}$ past the archway. (to mean (12a))

b. The only clean toilet is $\{$ all the way $/ *$ on the way $\}$ upstairs. (to mean $(12 b))$

c. The entrance is $\{$ all the way / *on the way $\}$ to the back of the building. (to mean $(12 c)$ )

d. You'll find her office $\{$ all the way / *on the way through this corridor. (to mean $(12 d)$ )

e. He can be found somewhere $\{$ all the way / *on the way $\}$ over this mountain. (to mean $(12 e)$ )

(15) a. There is an observation post $\{*$ all the way / on the way $\}$ downwards. (to mean (13a))

b. You may soon meet another obstacle $\{*$ all the way / on the way $\}$ ahead. 
c. The entrance is \{?all the way / on the way $\}$ towards the back of the building. ${ }^{28}$

d. You'll find her office $\{*$ all the way / on the way $\}$ along this corridor. (to mean (13d))

e. He can be found somewhere $\{*$ all the way / on the way $\}$ about that farm.

To summarize this section, there is evidence that we can distinguish four groups of directional prepositions. There are three groups which contain directional prepositions denoting an extended path, and which can be distinguished according to whether this path has either a definite endpoint (e.g. across) or not (e.g. about in the 'random directions' sense) or allows both readings (e.g. down). The fourth group contains directional prepositions that evoke an abrupt (punctual) change of location and which we have therefore called nonextended path directional prepositions. The majority of the latter prepositions are in fact locative expressions that can acquire a translocational interpretation in a motion construction. 'Extended path' prepositions tend to alternate between a transitive and an intransitive use, whereas 'nonextended path' prepositions tend to be either purely transitive (e.g. at, from) or purely intransitive (e.g. apart, back). These properties are summed up in Table 1.

Table 1. The four classes of directional P/rt's and their properties

\begin{tabular}{|c|c|c|c|c|}
\hline & Class 1 & Class 2 & Class 3 & Class 4 \\
\hline $\begin{array}{l}\mathrm{P} / \mathrm{rt} \text { can typically be used } \\
\text { either as a particle or as a } \\
\text { preposition }\end{array}$ & yes & yes & yes & $\begin{array}{l}\text { no, but those } \\
\mathrm{P} / \mathrm{rt} \text { 's that do } \\
\text { alternate often } \\
\text { take of }\end{array}$ \\
\hline $\begin{array}{l}X \text { is } P / r t N P \text { reads as ' } \mathrm{X} \text { is } \\
\text { all the way } \mathrm{P} \text { NP' }\end{array}$ & yes & no & sometimes & no \\
\hline $\begin{array}{l}X \text { is } P / r t N P \text { reads as ' } \mathrm{X} \text { is } \\
\text { on the way } \mathrm{P} \text { NP' }\end{array}$ & no & yes & sometimes & no \\
\hline
\end{tabular}

Class 1: P/rt's referring to an extended path with a definite end-boundary

Class 2: P/rt's referring to an extended path without a definite end-boundary

Class 3: P/rt's referring to an extended path with or without a definite end-boundary

Class 4: $\mathrm{P} / \mathrm{rt}$ 's referring to a nonextended path

In what follows we will investigate how these different sorts of directional P/rt's can play a role in the (non)boundedness of a motion event. In fact, the class of nonextended path P/rt's will not be studied, since they denote an instantaneous change of location whereas the notion of (non)boundedness presupposes duration. We will thus restrict our discussion to 'extended path' P/rt's.

\section{Extended path $P / r t$ 's as particles}

For reasons that will become clear in the next section, we will start our discussion with extended path $\mathrm{P} / \mathrm{rt}$ 's that are (used as) particles. As we have seen in the previous section, some extended path P/rt's refer to a path with an end-boundary, some refer to a path without an end-boundary and still others are unspecified with respect to the presence of 
an end-boundary. The first group comprises the prepositions listed in (16a), the second group those listed in (16b) and the third those in (16c):

(16) a. about (' $180^{\circ}$ rotation around one's axis'), across, around ('encirclement'; ' $180^{\circ}$ or $360^{\circ}$ rotation around one's axis'), downstairs, over, past, round ('encirclement'), through, up ('to a contextually salient point'), upstairs

b. about ('random directions'), after, ahead, along, around ('random directions'), backward(s), downward(s), forward(s), on ('continuation'), round ('random directions'), upward(s); perhaps also away and back.

c. by, down, downhill, up ('to a higher position'; 'towards a contextually salient point'); perhaps also home (remember that a path can be evoked by making the endpoint of the path explicit)

The membership in one of these classes appears to determine the (non)boundedness of motion events (cp. Jackendoff 1996). Below are authentic data that prove this. Note that the grammaticality judgments of the made-up sentences within brackets are in accordance with the recommendations formulated in footnote 6 . In particular, they do not pertain to possible result-state related or iterative readings. The examples in (17) show that particles expressing an extended path with an end-boundary are (fully) compatible with 'in X time' adverbials only, in other words, that these prepositions lead to a temporally bounded construal of the motion event (under the proviso that the moving entity is conceived of as having well-defined spatial boundaries - cf. section 7).

(17) a. Hovercraft are being used as passenger ferries, for instance across the English Channel, where they transport passengers, goods and vehicles across in less than half an hour. (www) (Compare: *Everybody was transported across for half an hour.)

b. Mercury, the closest planet to the Sun zips around in only 88 days, while distant Pluto takes about 247 years. (www) ('encirclement' sense) (Compare: *Mercury zips around for 88 days)

c. In 1979, Ji Ming, the youngest of the three brothers, swam over in only five hours. (www) (Compare: *Ji Ming swam over for five hours.)

d. He raced downstairs in less than five seconds and was overjoyed to find the guard station still clear. (www) (Compare: ?"He raced downstairs for five seconds)

e. Although most passengers walk through in less than five minutes, Customs in Miami has seized 6,000 pounds of narcotics from passengers this year. (www) (Compare: *The passenger walked through for five minutes.)

The examples in (18) show that particles expressing an extended path without an endboundary impose a temporally nonbounded construal on a motion event, because they can be felicitously combined with 'for X time' adverbials only. The same restrictions on grammaticality judgments as above apply. In particular, possible inchoative readings (e.g. They made love in less than a week in the sense of 'It lasted less than a week before they made love') of the contrasted made-up sentences are disregarded. 
(18) a. We drove about for a while, looking for parking. (www) (Compare: *We drove about in ten minutes.)

b. He went ahead for a while, but suddenly he came upon a heap of boulders blocking the way. (www) (Compare: *He went ahead in twenty minutes.)

c. After that we just meandered around for a while. (www) ('random directions' sense) (Compare: *We meandered around in twenty minutes.)

d. After entering the Tsung-ling Mountains, step by step, we crept upwards for four days, and then reached the highest part of the range. (www) (Compare: *We crept upwards in four days.)

e. She walked along for a while and thought about hopping a bus home. (www) (Compare: She walked along in twenty minutes)

The essentially locative expressions away and back can also be used with a 'for X time' adverbial, but then a resultative reading normally arises. For example, She went away for a month or She came back for a month implies that the subject referent stayed away from or stayed with, respectively, the salient reference point for a month. However, an eventrelated reading is occasionally possible if (especially with away) the time interval is relatively short:

(19) The dogs ran away for a few seconds and I jumped out and grabbed Gruff. (www)

(20) They grudgingly walked back for a minute or so, then turned right and continued on until they hit another stairwell. ${ }^{29}$ (www)

That away and back do indeed have the capacity to express an extended path rather than refer to an instant change of location with motion verbs is evidenced by sentences with a measure phrase specifying the distance covered. Such sentences occur more frequently than those in (21) and (22).

(21) And so the two ran away for a few miles. (www)

(22) We walked back for about a hundred yards (...) (www)

The remaining intransitive extended-path-expressing prepositions, those listed in (16c), are compatible both with temporally bounded and temporally nonbounded event construals, depending on the context at hand.

(23) a. Every second he wasn't with her went on for a lifetime, and every second he was with her flashed by in less than an instant. (www) / Again, the same region of space, but this time, a partly blurred image of a ship flew into the frame, and we all froze. It merely drifted by for a second, and then it turned itself to face the "eye" of the Probe. (www)

b. If you go downhill in one hour rather than three, you're three times less likely to hurt yourself. (www) / We started from Long Gulch and ran downhill for appx. two hours to the Safeway where we had camped overnight. (www)

c. I climbed up in less than a couple hours since this mountain is a piker compared to the one where I have my lair. (www) / I rode up for a couple of hours and then attempted to come back via the next ridge over. (www)

Note, by the way, that past, which is semantically close to by, could not substitute for by in the second example of (23a) (*It merely drifted past for a second). Apparently, these 
path expressions differ in their effect on temporal boundedness. Note also that up does not refer to a path with a definite end-boundary. This contradicts the intuition of, among many others, Villavicencio and Copestake (2003) that up necessarily yields an accomplishment (i.e. telic) reading, and hence leads to temporal boundedness under normal circumstances. In fact, they see $u p$ - whether expressing upward direction, as in (23c), or not, as in the example in footnote 23-as predicating an endpoint not of the path but directly of the event, perhaps like up in drink up. The view that nondirectional up has an overall telicizing aspectual effect is particularly strong but somewhat misguided, as argued by Cappelle (in preparation b).

When the essentially locative expression home is used as an extended path expression, the path can also have or lack an end-boundary, resulting (under well-defined conditions) in the motion event being temporally bounded or nonbounded:

(24) a. Toni drove home in less than twenty minutes. (www)

b. Kiila walked home for a while by herself. (www)

It might be argued that some of the prepositions in (16c) do refer to a path with an end-boundary and that the addition of a 'for $\mathrm{X}$ time' adverbial is coercive, in forcing a reading in which this end-boundary is removed from our scope of view. This would mean, for example, that I walked up, by itself, is taken to mean 'I walked all the way up (to the top or to a salient reference point)' but that this reading is only an implicature and, hence, cancellable by the context. We do not exclude this possibility. This may be substantiated by extensive corpus research (does an 'in X time' adverbial follow more often than a 'for $\mathrm{X}$ time' adverbial?) or by psycholinguistic testing (does the addition of an 'in $\mathrm{X}$ time' adverbial trigger shorter reaction times than the addition of a 'for $\mathrm{X}$ time' adverbial?).

\section{Extended path $\mathbf{P} / \mathbf{r t}$ 's as prepositions and the role of the landmark NP}

Let us now turn to sentences in which the P/rt is followed by an NP expressing the landmark over which the moving entity moves - hence, in which the P/rt is (used as) a preposition. As we have already mentioned in section 4, many $\mathrm{P} / \mathrm{rt}$ 's expressing an extended path can alternate between a use as a preposition and a use as a particle. It is often claimed, or silently supposed, that a particle can be used instead of a corresponding full prepositional phrase whenever the object of the preposition is recoverable in the context (e.g. Gries, 2003: 18; Lee, 1999, 136; O’Dowd, 1998: 3-4; Sinclair, 1990: 164, 169). This is not the case, as we will show here. Although it often is possible to replace a full PP by a particle, there are some sentences in which a preposition but not the corresponding particle can be used, even though the missing object could be easily retrieved from the context. Here are some examples.

(25) a. On one occasion she walked across the desert for seven days. (www) / [The vastness of the desert doesn't frighten her.] *On one occasion she walked across for seven days.

b. So small is the island that you can hike along the coast in less than half a day. (www) / [The beach makes for a nice walk.] *You can hike along in less than half a day, so small is the island. 
c. British Airways has confirmed that the plane will fly over the Atlantic for nearly three and half hours before returning to its base. (www) / *British Airways has confirmed that the transatlantic plane will fly over for nearly three and a half hours before returning to its base.

d. He ran through the forest for hours and finally met with her. (www) / *He entered the forest, ran through for hours and finally met with her.

How can we explain this difference between the use of these $\mathrm{P} / \mathrm{rt}$ 's as prepositions and their use as particles? The answer lies in the fact that full prepositional phrases, as in the first option in each of the pairs of sentences above, contain an NP which may have the capacity to override the spatial delimitation of the path expressed by the P/rt. In the previous section, we saw that across, over and through, used as particles, express a delimited path, i.e. a path with a definite end-boundary. The unexpressed landmark is then assumed to have a clear end-boundary as well, which coincides with the end of the path. However, by making the landmark explicit (the desert, the Atlantic, the forest), the speaker can let the hearer dwell as it were on the landmark's extendedness (i.e. its being extended to a high degree) and draw his attention away from the landmark's boundaries. A desert may conjure up the mental vision of vast planes of sand, rather than of a delimited plane. Similarly, the most salient feature of an ocean or a forest may be extendedness rather than delimitation.

This is not to say that the presence of such an object NP renders a temporally bounded construal impossible. There is, of course, nothing wrong with She walked across the desert in seven days, The Concorde could fly over the Atlantic in five hours, or He ran through the forest in two hours. However, across, over and through, though they express a path with clear boundaries by themselves, may also be followed by an NP expressing a landmark without clear boundaries. In that case, the motion event cannot be temporally bounded:

(26) a. She walked across desert land \{for seven days / *in seven days\}.

b. The plane will fly over Atlantic waters \{for nearly three and a half hours / *in five hours .

c. He ran through thick forest $\{$ for hours / *in two hours\}.

Alternatively, when the P/rt along is followed by an NP making the landmark explicit, as in the first sentence of (25b), the default sense of the path being not delimited may be cancelled. In that case, the object NP gives the hearer mental access to the landmark's boundaries, if any, which would be outside the hearer's focus of attention if the landmark were not mentioned explicitly. In (25b) the landmark is the beach of an island, which goes all the way round the island and therefore has no (nonarbitrary) beginning or end. Still, speakers have the capacity to construe an entity that by itself is not spatially delimited as containing boundaries all the same - in this case, an arbitrary point of departure and the very same point functioning as point of arrival. (This example shows in a very illuminative way that certain seemingly simple and uncontroversial entities, like an object's spatial boundaries, are not always given in the world but may be constructs of the way we humans choose to perceive the world.) In any case, the use of an explicit (i.e. overtly expressed) landmark is a necessary requirement for the overriding of along's default sense, even if the mention of this landmark may be contextually redundant. In fact, along used as a particle does not presuppose a landmark at all, as observed by Dec- 
lerck (1976: 74-75). For example, walk along simply means 'walk further', 'walk onwards', whether or not there is an extended object along which the walking may proceed.

Even if the $\mathrm{P} / \mathrm{rt}$ is merely followed by a pronoun functioning as anaphor, the (non)boundedness of the path can be overridden:

(27) a. The vastness of the desert didn't frighten her. On one occasion she walked $\{$ *across / across $i t\}$ for seven days.

b. [The beach makes for a nice walk.] You can hike $\{*$ along / along it $\}$ in less than half a day, so small is the island.

c. The Atlantic is a vast unpopulated area and therefore an ideal test flight zone. The Concorde will fly $\left\{{ }^{*}\right.$ over / over it $\}$ for nearly three and a half hours.

d. He entered the forest and ran $\{*$ through / through $i t\}$ for hours and finally met with her.

This observation shows that overriding the default sense of a $\mathrm{P} / \mathrm{rt}$ is not simply a matter of whether or not the $\mathrm{P} / \mathrm{rt}$ is followed by overt lexical material which itself conjures up the idea of spatial delimitation or spatial extendedness. What matters is whether the $\mathrm{P} / \mathrm{rt}$ is used as a preposition or not, and a simple anaphoric it, even if it is dispensable for the retrieval of the landmark, can make all the difference.

The above observations cast some light on the distinction between particles and prepositions. It appears that particles and prepositions are really quite distinct categories, even though in the linguistic literature, as we have pointed out above, their distinctness is often denied beyond the mere statement that particles do not have an explicit object NP. The conclusion that particles are not just intransitive prepositions ties in with a couple of other findings. First, it has been shown by Declerck (1976) that directional particles cannot always be "reconstructed" as full prepositional phrases (e.g. The balloon went up. *Up what?). Secondly, it has been pointed out more recently in Cappelle (2002b) that particles and prepositions do not have exactly parallel restrictions in the preposing construction, as in $U p$ (the tree) it climbed: while this pattern disallows nondirectional prepositions, it does allow certain nondirectional particles (e.g. [*Without stopping / on\} danced the rhythm in his head). ${ }^{30}$ Cappelle (to appear; in preparation a) gives a good dozen more differences in syntactic distribution between particles and full PPs.

Another interesting observation is that one and the same landmark can be used to direct the hearer's attention to the idea of spatial extendedness in one sentence and to the idea of spatial delimitation (on top of extendedness) in another:

(28) a. We walked across the desert for days, with no food or water. (www)

b. While international tourists might rock up to Birdsville on motorcycles equipped only with a tiny water bottle hoping to ride across the desert in a day, Crombie and fellow Birdsville locals know the desert is not to be trifled with. (www)

What we could conclude from this pair of examples is that desert, as a count noun, is underdetermined as to whether or not it denotes an area that is essentially spatially delimited. (As a mass noun, as in We walked across desert, it clearly denotes a spatially undelimited area.). If the area denoted by the desert is conceived of as a spatially undelimited area, as in (28a), it cancels the sense of spatial delimitedness of the path expressed by the P/rt across. Alternatively, we might choose to locate the vagueness in the preposi- 
tion across by claiming that across NP by itself expresses an extended path with or without a clear end-boundary, leaving it to the NP to either leave intact this indeterminacy (as in across the desert) or fix the (un)delimitedness value (cp. across the entire desert vs. across desert). Of course, this option would mean that the preposition across is even more semantically distinct from the particle across, the latter of which is certainly not underdetermined as to the path having or lacking an end-boundary — see again (17a).

\section{The role of the moving entity NP}

Consider the following examples (ignoring all irrelevant readings-result-state, inchoative, etc.):

(29) a. All the water streamed through $\{$ in $/ *$ for $\}$ ten seconds.

b. Water streamed through $\{*$ in $/$ for $\}$ ten seconds.

Apparently, the events described by All the water streamed through and by Water streamed through differ in boundedness, the first being temporally bounded, the latter being temporally nonbounded. The reason is clear: the definite NP all the water denotes a spatially delimited mass, while the indefinite NP water does not. Motion events behave no differently from any other event, for which it has been known for some time in the aspectual literature (e.g. Verkuyl, 1972) that the presence or absence of clear boundaries in the verb's arguments plays a crucial role. Hence, the nature of the NP expressing the moving entity is a determining factor in an event's boundedness, irrespective of whether this moving entity appears as the verb's subject (as in (29a-b)) or as its object (as in (30ab)):

(30) a. We pumped all the water through $\left\{\right.$ in $/{ }^{\text {f }}$ for $\}$ ten seconds.

b. We pumped water through $\{*$ in $/$ for $\}$ ten seconds.

(The reason why the 'for X time' in (30a) does not sound as unacceptable as in (29a) is that a conative interpretation is possible here, but not in (29a): 'Our attempt to pump all the water through lasted ten seconds' makes sense as a paraphrase, but not 'The water's attempt to stream through lasted ten seconds'. Possible conative readings constitute a complication in the 'in/for X time' test that is well worth exploring.) What is measured by the durational adverbial in (29) and (30) is the time during which different (i.e. increasingly more) parts of the moving entity undergo translocational motion, rather than the time during which different (i.e. increasingly more) parts of the path are traveled.

Of course, it is not just mass nouns that can be represented as having or lacking spatial boundaries. It is beyond the scope of this study to figure out what imposes boundaries on an NP, and especially which role determiners (including quantifiers) play in this. We will not try here to give a full account of what factors are responsible for spatial delimitation in the moving entity, but it is clear that more than just the role of determiners would have to be taken into account. The following examples are only meant to give the reader an idea of the complexity of such an enterprise:

(31) a. The entire pack of bikers flashed by \{in five seconds / *for some time\}.

b. $\quad$ All the bikers flashed by $\{$ in five seconds / *for some time $\}$.

c. Twenty bikers flashed by $\{$ in five seconds $/ *$ for some time $\}$. 
d. More than twenty bikers flashed by $\{$ in five seconds / * for some time $\}$.

e. Several bikers flashed by \{in five seconds / for some time $\}$.

f. Biker after biker flashed by $\{*$ in five seconds / for some time $\}$.

g. A seemingly endless stream of bikers flashed by \{in five seconds / for some time\}.

A key notion is conceptualization, or 'mental construal', in a cognitive grammar sense. The importance of this notion has already been revealed in our discussion of (28a-b), where it was shown that one and the same real-world entity (namely a desert) can be thought of in terms of its indefinite extension or in terms of its delimitation. The role of conceptualization reaches even further in the following pair of authentic examples:

(32) a. [The train car had been incredibly hot, the air conditioner noisily spurting out hotter air, a pen cap lodged somewhere within.] The Alps had flashed by in an hour. (www)

b. [After a 10 minute break we were on our way again. The skies had cleared by now and I'd taken off the thermal top.] Undulating farmland passed by for a while [, and I was still leading our small pack of three.] (www)

First of all, the difference in temporal boundedness in these sentences can only be attributed to the subject entity - the difference between flash and pass cannot account for this boundedness difference: both verbs could be used in either example, although flash is most suitable for the first and pass the more suitable for the second (owing to the fact that flash evokes speed better than pass). Note, however, that in the "real world", neither the Alps nor the farmland are truly moving entities. It is only the conceptualizer, being in a moving vehicle, who conceives of them as moving entities. Furthermore, while the Alps are thought of as something well-delineated in (32), there is no nonarbitrary point in the real world where one can say: "The Alps extend (from this point onwards / up to this point \}". Conversely, the farmland in (32b) is construed as something with unclear boundaries, although in real life boundaries between farmland and building land are often clearly defined by law.

The role of the NP denoting the moving entity is most visible in motion events that make use of a directional PP denoting a nonextended path. In such a case, if the moving entity has no real extension either, the event does not have a real duration, so that the 'inlfor X time' adverbial test cannot be applied, since both sorts of adverbial require duration. The following sentences are therefore unacceptable, at least on an event-related reading:

(33) I went aboard $\{*$ in half an hour / *for half an hour $\}$.

Obviously, when the path has no real extension to speak of, it does not make much sense to measure the time (by means of a durational adverb) that is needed to cover this path. Therefore, it is only when the moving entity NP is extended that the durational adverbial test becomes useful, namely to test whether or not there comes an end to the parts or items that in an increasing number participate in the moving event:

(34) a. All the passengers went aboard $\{$ in $/ *$ for $\}$ half an hour.

b. Passengers went aboard $\{*$ in $/$ for $\}$ half an hour. 


\section{Conclusion}

Our aim in this article has been to show how aspects of the English directed motion construction can help to determine the temporal (non)boundedness of the representation of events. By 'directed motion construction' we have understood any construction of the form Subject NP + Verb $(+$ Object NP) + Oblique in which the Subject NP or, if present, the Object NP refers to the moving entity, the Verb is nonstative, and the Oblique is a directional phrase introduced by, or made up of, a ' $\mathrm{P} / \mathrm{rt}$ ' referring to the path followed by the moving entity. The symbol ' $\mathrm{P} / \mathrm{rt}$ ' is short for any item which is either a preposition (in the traditional sense) or a particle (whereby the category 'particle' includes, in this study, adverbs that cannot precede an object NP). Temporal (non)boundedness is an aspectual notion having to do with whether or not an event, as referred to by a finite clause, is conceptualized and represented as reaching an endpoint. Unsurprisingly, temporal (non)boundedness is intimately related to, though not exclusively determined by, the (a)telicity of the VP, that is, whether or not it refers to an event that has an inherent or intended endpoint. Temporal (non)boundedness can generally be tested by adding an 'in $\mathrm{X}$ time' adverbial, in which case the event is represented as bounded, or a 'for $\mathrm{X}$ time' adverbial, in which case the event is represented as nonbounded. Here are the most important points that have come up in the course of our study.

1. The temporal (non)boundedness of motion events (i.e. events referred to by a directed motion construction) is influenced by the (a)telicity of the VP, which in turn depends on the presence or absence of an end-boundary in the speaker's conceptualization of the path.

2. Intransitive directional prepositions can be classified according to whether they, by themselves, refer to a path with a definite end-boundary (e.g. through), a path without a definite end-boundary (e.g. about in stroll about), or a path which may or may not have a definite end-boundary (e.g. up). Still other intransitive directional prepositions do not refer to a path with extension; most of these are basically locative but seem to receive a directional interpretation in the directed motion construction (e.g. inside).

3. Contrary to what is often assumed, the choice between a particle and its full PP variant is not exclusively motivated by the contextual accessibility of the landmark. Sometimes, a landmark NP is supplied, even if it would have been otherwise recoverable, with the purpose to impose or take away the conceptualization of an end-boundary. For example, while fly over presupposes the existence of a boundary (which may also be a 'point' in space, e.g. a building as seen from the sky) which, if flown over, characterizes the mission as accomplished, hence as temporally bounded, the event fly over uncharted terrain removes this presupposition and is hence conducive to a nonbounded construal.

4. Whether or not an explicit landmark NP imposes or takes away the conceptualization of an end-boundary cannot always be predicted. With mass nouns, there is never reference to an end-boundary, but clear delineation in the reference of count nouns is often a matter of how we conceive of these entities. For example in Sheila walked across the desert, the desert referred to may or may not include its boundaries in the speaker's conceptualization of it, hence the possibility to add either an 'in X time' or a 'for X time' adverbial.

5. As may be expected, the spatial delineation of the moving entity can also affect the temporal boundedness of the motion event (compare, e.g., a cloud drifted over with clouds drifted over). 


\section{References}

Bennett, David C., 1975. Spatial and Temporal Uses of English Prepositions: An Essay in Stratificational Semantics. Longman, London. Longman Linguistics Library 17.

Bolinger, Dwight, 1971. The Phrasal Verb in English. Harvard University Press, Cambridge, Mass.

Cappelle, Bert, 2001. Is out of always a preposition? Journal of English Linguistics 29(4), 315-328.

Cappelle, Bert, 2002a. Paths and goals (and parts and wholes), and the aspectual difference between certain prepositions and particles. Paper presented at the International Conference on Adpositions of Movement. K.U. Leuven, January 14-16, 2002.

Cappelle, Bert, 2002b. And up it rises: Particle preposing in English. In: Dehé, Nicole, Jackendoff, Ray, McIntyre, Andrew, Urban, Silke (Eds), Verb-Particle Explorations. Mouton de Gruyter, Berlin and New York, pp. 43-66. Interface Explorations 1 .

Cappelle, Bert, to appear. The particularity of particles, or why they are not just "intransitive prepositions". To appear in Belgian Journal of Linguistics.

Cappelle, Bert, in preparation a. Particle Patterns in English. Ph.D. dissertation. K.U. Leuven.

Cappelle, Bert, in preparation b. What's up? Redefining the aspectual particle par excellence. Ms. K.U. Leuven Campus Kortrijk.

Casad, Eugene H, 1993. 'Locations', 'paths' and the Cora verb. In: Richard A. Geiger and Brygida Rudska-Ostyn (Eds), Conceptualizations and mental processing in language, pp. 593-645. Mouton de Gruyter, Berlin and New York.

Comrie, Bernard, 1985. Tense. Cambridge University Press, Cambridge. Cambridge Textbooks in Linguistics.

Cowper, Elizabeth Ann, 1992. A Concise Introduction to Syntactic Theory: The Government-Binding Approach. University of Chicago Press, Chicago.

Declerck, Renaat, 1976. A Proposal Concerning the Underlying Structure of Literal Phrasal Verbs. K.U. Leuven Campus Kortrijk. Preprint No. 2.

Declerck, Renaat, 1977. The superfluity of a 'path' case in English and the analysis of complex movement expressions. Leuvense Bijdragen (Leuven Contributions in Linguistics and Philology) 66, 129-154.

Declerck, Renaat, 1979. Aspect and the bounded/nonbounded (telic/atelic) distinction. Linguistics 17, 761-794.

Declerck, Renaat, 1989. Boundedness and the structure of situations. Leuvense Bijdragen (Leuven Contributions in Linguistics and Philology) 78, 225-308.

Declerck, Renaat, 1997. When-Clauses and Temporal Structure. Routledge, London and New York.

Declerck, Renaat, Cappelle, Bert, in preparation. (A)telicity and (non)boundedness. Ms. K.U. Leuven Campus Kortrijk.

Declerck, Renaat, Reed, Susan, forthcoming. The Grammar of the English Tense System. Mouton de Gruyter, Berlin and New York.

Depraetere, Ilse, 1995. On the necessity of distinguishing between (non)boundedness and (a)telicity. Linguistics and Philosophy 18, 1-19.

Depraetere, Ilse, 2000a. Review article of Michaelis, L. A. 1998. Aspectual grammar and past-time reference and Elsness, J. 1997. The perfect and the preterite in contemporary and earlier English. Lingua 110, 449-465. 
Depraetere, Ilse, 2000b. Bornage, temps et aspect. Dissertation Université Charles de Gaulle - Lille III.

Depraetere, Ilse, Reed, Susan, 2000. The present perfect progressive: constraints on its use with numerical object NPs. English Language and Linguistics 4(1), 97-114.

Dowty, David R., 1979. Word Meaning and Montague Grammar: The Semantics of Verbs and Times in Generative Semantics and in Montague's PTQ. D. Reidel, Dordrecht. Synthese Language Library: Texts and Studies in Linguistics and Philosophy 7.

Ekberg, Lena, 2001. Transformations on the Path-schema and a minimal lexicon. Studia Linguistica 55(3), 301-323.

Emonds, Joseph E., 1970. Root and Structure-Preserving Transformations. Ph.D. dissertation. Massachusetts Institute of Technology.

Emonds, Joseph E., 1972. Evidence that indirect object movement is a structurepreserving root. Foundations of Language 8, 546-561.

Gabbay, Dov, Moravcsik, Julius, 1980. Verbs, events, and the flow of time. In: Rohrer, Christian (Ed.), Time, Tense, and Quantifiers. Proceedings of the Stuttgart Conference on the Logic of Tense and Quantification. Max Niemeyer, Tübingen. Linguistische Arbeiten 83.

Garey, Howard B., 1957. Verbal Aspect in French. Language 33(1), 91-110.

Goldberg, Adele E., 1995. Constructions: A Construction Grammar Approach to Argument Structure. The University of Chicago Press, Chicago and London. Cognitive Theory of Language and Culture.

Gries, Stefan Thomas, 2003. Multifactorial Analysis in Corpus Linguistics: A Study of Particle Placement. Continuum Press, London. Open Linguistics Series.

Gruber, Jeffrey S., 1976. Lexical Structures in Syntax and Semantics. North-Holland Amsterdam etc. North-Holland Linguistic Series 25.

Heaton, J. B., 1965. Prepositions and Adverbial Particles. Longmans, London.

Hinrichs, Erhard W., 1985. Compositional semantics for Aktionsarten and NP Reference in English. Ph.D. dissertation. Ohio State University.

Huddleston, Rodney, Pullum, Geoffrey K., 2002. The Cambridge Grammar of the English Language. Cambridge University Press, Cambridge.

Jackendoff, Ray S., 1973. The base rules for prepositional phrases. In: Anderson, Stephen R., Kiparsky, Paul (Eds), Festschrift for Morris Halle. Holt, Rinehart and Winston, New York etc., pp. 345-356.

Jackendoff, Ray S., 1983. Semantics and Cognition. MIT Press, Cambridge, Mass and London. Current Studies in Linguistics 8.

Jackendoff, Ray S., 1990. Semantic Structures. MIT Press, Cambridge, Mass and London. Current Studies in Linguistics 18.

Jackendoff, Ray S., 1996. The proper treatment of measuring out, telicity, and perhaps even quantifcation in English. Natural Language and Linguistic Theory 14(2), 305-354.

Johnson, Mark, 1987. The Body in the Mind: The Bodily Basis of Meaning, Imagination and Reason. The University of Chicago Press, Chicago and London.

Klima, E. S., 1965. Studies in Diachronic Syntax. Ph.D. dissertation. Harvard University.

Lakoff, George, 1987. Women, Fire, and Dangerous Things: What Categories Reveal about the Mind. The University of Chicago Press, Chicago and London.

Langacker, Ronald W., 1987. Foundations of Cognitive Grammar. Vol. I. Theoretical Perspectives. Stanford University Press, Stanford. 
Langacker, Ronald W., 1990. Concept, Image, and Symbol. The Conceptual Basis of Language. Mouton de Gruyter, Berlin and New York.

Langacker, Ronald W., 1999. Virtual reality. Studies in Linguistic Sciences 29: 77-103.

Langacker, Ronald W., 2002. Concept, Image, and Symbol: The Cognitive Basis of Grammar. ( $2^{\text {nd }}$ edition with a new preface.) Mouton de Gruyter, Berlin and New York. Cognitive Linguistics Research 1.

Lee, David, 1999. Intransitive prepositions: Are they viable? In: Collins, Peter, Lee, David (Eds.), The Clause in English: In Honour of Rodney Huddleston. John Benjamins: Amsterdam, pp. 133-147. Studies in Language Companion series, 45.

Lindkvist, Karl-Gunnar, 1976. A Comprehensive Study of Conceptions of Locality in which English Prepositions Occur. Stockholm: Almqvist och Wiksell International. Acta Universitatis Stockholmiensis. Stockholm Studies in English, 35.

Lindstromberg, Seth, 1998. English Prepositions Explained. John Benjamins: Amsterdam.

Matsumoto, Yo, 1996. How Abstract is Subjective Motion? A Comparison of Coverage Path Expressions and Access Path Expressions. In: Goldberg, Adele (Ed.), Conceptual Structure, Discourse and Language, CSLI Publications, Stanford, pp. 359373.

McArthur, Tom, 1989. The long-neglected phrasal verb. English Today 18, 38-43.

Miller, George A., Johnson-Laird, Philip N. 1976. Language and Perception. Cambridge University Press, Cambridge.

Mourelatos, Alexander P. D., 1981. Events, Processes, and States. In Tedeschi, Philip J. and Zaenen, Annie (Eds), Syntax and Semantics. Volume 14. Tense and Aspect. Academic Press, New York.

O’Dowd, Elizabeth M., 1998. Prepositions and Particles in English: A DiscourseFunctional Account. Oxford University Press, New York.

Sinclair, John, Ed.-in-chief, 1990. Collins COBUILD English Grammar. Collins, London

Talmy, Leonard, 1996. Fictive motion in language and 'ception'. In: Bloom, Paul, Peterson, Mary A., Nadel, Lynn, Garrett, Merrill F. (Eds), Language and Space. MIT Press, Cambridge, Mass, pp. 211-276.

Vanden Wyngaerd, Guido, 2001. Measuring events. Language 77(1), 61-90.

Van der Leek, Frederike, 2000. Caused-motion and the 'bottom-up' role of grammar. In: Van der Leek, Frederike, Foolen, Ad (Eds), Constructions in Cognitive Linguistics. Selected Papers from the Fifth International Cognitive Linguistics Conference, Amsterdam, 1997. John Benjamins, Amsterdam and Philadelphia, pp. 301331. Amsterdam Studies in the Theory and History of Linguistic Science, Series IV: Current Issues in Linguistic Theory 178.

Vendler, Zeno, 1967. Linguistics in philosophy. Cornell University Press, Ithaca, NY.

Verkuyl, Henk J., 1972. On the Compositional Nature of the Aspects. D. Reidel, Dordrecht. Foundations of language. Supplementary series 15.

Verkuyl, Henk J., 1993. A Theory of Aspectuality: The Interaction between Temporal and Atemporal Structure. Cambridge University Press, Cambridge. Cambridge Studies in Linguistics 64.

Villavicencio, Aline, Copestake, Ann, 2003. Verb-particle constructions in a computational grammar of English. In: Kim, Jong-Bok, Wechsler, Stephen (Eds), The Proceedings of the $9^{\text {th }}$ International Conference on HPSG. CSLI Publications, Stanford, pp. 357-371. 


\section{Notes}

${ }^{1}$ We would like to thank Ilse Depraetere and Susan Reed for their constructive comments on earlier versions of this text. We are also grateful to two anonymous reviewers of this journal for their helpful suggestions as well as to two anonymous reviewers of another journal whose comments we received and could benefit from even after we had already withdrawn our manuscript to update its contents.

${ }^{2}$ Particles that express direction are sometimes called "adverbs" because of their presumed higher independence from the verb than idiomatic particles (such as up in look something up). As argued in Declerck (1976: 6-8) and Cappelle (in preparation a), the syntactic differences between directional and idiomatic particles are more apparent than real. In analogy with verbs, particles are also sometimes analysed as "intransitive prepositions". However, see Cappelle (to appear) for some reasons why treating particles as a sort of PPs (namely PPs headed by an intransitive preposition) obscures a number of important differences between particles and full PPs. The fact that particles may imply a bounded path while their corresponding full PPs may not, as evidenced by (1), is a case in point.

${ }^{3}$ A transitive motion event (of the structure Subject NP + Verb + Object NP + Oblique) is sometimes called a 'caused motion' event rather than a 'directed motion' event. In John followed Mary into the room, however, the movement of the object NP is not caused by the activity performed by the subject NP. Though there are two separate moving entities here, only John is to be understood as the (i.e. the primary) moving entity.

${ }^{4}$ When the motion event is essentially one of covering an area, the path may be said to have two dimensions, as in (i) below.

(i) Some say you can walk around Bruges in an afternoon and have seen all the must-see monuments.

The event in this example comes to an end when the area has been wandered upon virtually entirely along its two axes, that is, along both its longitudinal and its transverse axis. Of course, one single person cannot locomote in more than one direction at the same time. Only a group of people, for example a squad, can 'fan out' and cover an area as they do so. This means that walk around (NP), as used in (i), really means 'walk in many different directions until the (contextually defined) important parts of the (implied) area have been ticked off a (real or mental) checklist'.

${ }^{5}$ In (3b) this is not the case if the cart did not move in spite of their pushing it, but such a reading is irrelevant to the discussion, since no 'motion event' is involved then. Note, also, that such an interpretation would be better encoded in a so-called conative construction:

(i) They pushed at the cart.

${ }^{6}$ An event is bounded if you can add in $X$ time and nonbounded if you can add for X time, but see Declerck and Cappelle (in preparation) for almost a dozen complications that have to be taken into account when applying this test. For the present study, it is important to bear in mind the following: (i) A possible iterative or repetitive-habitual reading (e.g. John spent his summer holiday on the Bahamas for many years) should be left out of consideration when judging the acceptability of an added 'for $\mathrm{X}$ time' adverbial.

(ii) A possible result state reading (e.g. Mary went to the States for a couple of months = 'She stayed there for a couple of months') should be left out of consideration when judging the acceptability of an added 'for X time' adverbial.

(iii) An inchoative reading (e.g. I was a professional player in less than no time = 'It took me less than no time to become one') should be left out of consideration when judging the acceptability of an added 'in $\mathrm{X}$ time' adverbial.

${ }^{7}$ Depraetere (1995: 2) points out that events may also be telic because of an intended rather than inherent endpoint, as when someone deliberately tries to stay five minutes under an ice-cold shower. This event is referred to by means of a static verb (stay) and would therefore be atelic if it were not for the fact that a well-defined end point is strived for: the end of the staying event coincides with the passage of five minutes. The importance of intentionality to the concept of telicity is 
illustrated in Depraetere (2000a) and Depraetere and Reed (2000). Again, it is crucial to note that just because an endpoint can be defined does not necessarily mean that this endpoint will actually be reached. Depraetere gives the example of someone saying, "John is always boasting he can remain in ice-cold water. At the moment, he is staying under the cold water for five minutes", where the event referred to in the second sentence has an intended endpoint (and is therefore telic) but is not represented as having reached that endpoint yet (and is therefore nonbounded).

${ }^{8}$ Only events that are referred to by a 'grounded' clause, in the Cognitive Linguistics sense (Langacker, 2002: 321; Taylor, 2002: 391), can be said to be (non)bounded. See Taylor (2002: 590) for a concise explanation of the interrelated terms 'ground' and 'grounding': "The ground is the circumstances of the speech event; a conceptualization is grounded if it is anchored with respect to the ground. Grounding is effected, in nominals, by determiners and (sometimes) by quantifiers; in clauses, by markers of tense and (in English) by modal verbs." Note that modal verbs, indeed, only occur in finite clauses (cp. Our baby can't talk yet. / *It's too early for our baby to can talk).

${ }^{9}$ The fact that (a)telicity, as we define it here, applies to VPs and (un)boundedness to clauses implies that The child(ren) will cross the street and Children will cross the street are not instances of a telic and an atelic clause, respectively, but of a bounded and an unbounded clause, respectively, both containing a telic VP. In other words, the use of a bare plural subject NP may affect the boundedness of a clause, but leaves the telicity of the VP intact.

${ }^{10}$ For more comment on this terminological simplification, see Declerck and Reed (forthcoming).

${ }^{11}$ Langacker's characterization of "bounded" entails that a (to use his term) "perfective" (hence inherently "bounded") event like drink a glass of whisky becomes "nonbounded" when appearing in a progressive clause, since by using the progressive, the speaker does not make reference to the beginning and the end of an event. Given that, by definition, a "nonbounded" process cannot longer be "perfective", the progressive has an "imperfectivizing" effect in Langacker's theory. This means, in effect, that the use of the progressive brings about that a process changes from one Vendlerian class (e.g. from an accomplishment) to another (viz. to a state). In our account, which carefully distinguishes (a)telicity from (non)boundedness, telic events remain telic (so: accomplishments remain accomplishments), even when they are represented as nonbounded by a clause in the progressive.

12 In Taylor's (2002) version of Cognitive Grammar, events like walk along the beach ("activities" in Vendler's terms) are treated as inherently nonbounded ("imperfectives"), for lack of an inherent endpoint. As far as we can see, the use of the past tense is not analysed as having a "bounding" effect by Taylor, so that his and our treatment of (5) in terms of nonboundedness are in accordance.

${ }^{13}$ There is no crucial difference between crossing an end-boundary and merely reaching it. Speakers of English seem to neutralize the difference between these concepts. A boundary-crossing expression can often be used when a boundary-reaching interpretation is intended and vice versa. For example, in (ia), the boundary-crossing expression across is used in the sense of reaching a boundary, while in (ib), the boundary-reaching expression to seems to invoke the idea of actually crossing a boundary.

(i) a. I swam across the pool a few times and then hopped out. (www)

b. His supposed dead body was carried from its cell and thrown into the Tiber by his guards of the San Leo Prison. He swam to the other side of the river and lived for a great many years after that. (www)

Accordingly, the following sentences are interpreted as essentially conveying the same idea.

(ii) a. Jules swam across the Channel.

b. Jules swam to the other side of the Channel.

Whether these sentences refer to a boundary-crossing event or a merely boundary-reaching one is rather irrelevant when it comes to determining whether or not they represent the motion event as temporally bounded. (They both do.)

${ }^{14}$ The addition of a for $X$ time adverbial is not entirely impossible (even on an event-related reading), but the most salient interpretation of swimming across the Channel is 'swimming all the way across it'. Therefore, we disregard the unlikely reading of swimming across the Channel as 'swimming in the general direction of the other shore'. 
${ }^{15}$ Notice that in the case of telic events (as in Jules swam across the Channel), the simple past tense implies (i.e., entails) that the event actually came to its (inherent) end, whereas in the case of atelic events, the same tense form only implicates that the event came to an end. This becomes clear if we try to cancel what is implied or implicated:

(i) a. Jules swam across the Channel yesterday. *In fact, he may still be swimming across it.

b. Ella walked along the beach yesterday. In fact, she may still be walking along it.

${ }^{16}$ O'Dowd (1998) uses 'P' to refer to a word that can be either a preposition or a particle. However, in view of the fact that 'PP' stands for 'prepositional phrase' (in the same way that 'NP' stands for 'noun phrase', 'VP' for 'verb phrase', etc.), the symbol ' $P$ ' has already been assigned the value 'preposition', so that it is confusing to use it as a cover term for prepositions and particles. Note, importantly, that our ' $\mathrm{P} / \mathrm{rt}$ ' not only refers to items (like through) that can alternate between a use as preposition and a use as particle but also includes items that can only be a preposition (like into) and items that can only be a particle (like back). Note, furthermore, that although a 'particle' is standardly defined as an item that can either follow or precede a direct object NP (e.g., She carried \{the chest up / up the chest\}), we deviate from this practice, for reasons of simplicity, in treating as particles any directional item that does not directly govern an NP, even if it cannot precede a direct object NP (e.g., She carried \{ the chest upstairs / *upstairs the chest\}).

${ }^{17}$ In Declerck (1977) it was argued that in fact all directional PPs that are traditionally thought to express a 'path' qualify as either locative or goal PPs. Consequently, 'path' was discarded as a superfluous category. As far as we know, however, such a radical position has never been adopted by other linguists. The classification proposed here is, hopefully, more workable, while reminiscent of this earlier position in that many directional prepositions are still analysed as items that are, in the first place, locatives. It may further be doubted whether these locatives are automatically imbued with a directional ('path') reading by virtue of being used in a motion construction, as Goldberg (1995) would claim. Van der Leek (2000: 316-317) is probably right to maintain that locative in, for example, retains its locative meaning in e.g. Don't put too much salt in your food, where the focus is more on the resulting state of the salt than on the path it follows. These are interesting and important questions, but we cannot go into them here.

18 Some extended path prepositions, too, can also be used as purely locative items: downstairs, upstairs, and home.

${ }^{19}$ This distinction coincides with the opposition made in Cappelle (2002a) between goal-oriented and path-oriented directional phrases. The former focus on the endpoint of the path, while the latter focus on the path itself (i.e. its extension, not its endpoint, if any).

${ }^{20}$ Literature on prepositional semantics have laid bare the highly polysemous nature of most spatial prepositions. Various scholars (e.g., Bennett, 1975, Lindkvist 1976; Jackendoff, 1983; Lindstromberg, 1998) distinguish a route reading for many of the directional items classified here as exlocatives with a non-extended ('binary') path semantics (e.g. behind, between, near, under). A case example is under the table in, e.g., The rat ran under the table, which can refer to the location of the rat's running, to its goal (corresponding to our non-extended path sense) and to an intermediate position (as in ...under the table to the corner). We believe, however, that this 'via' sense is only a contextually induced extension of the non-extended path meaning, but further research is needed here.

${ }^{21}$ However, see note 29 for a reason why back may also be analysed as an extended path expression.

${ }^{22}$ Note, however, that if around is used in a related 'covering' sense, the path does have an endboundary; see the example in note 4 . Incidentally, around cannot be replaced by the otherwise near-synonymous about in this use.

${ }^{23}$ An example of this is:

(i) Kim was standing in the bottom of the valley. Sandy galloped up. (Villavicencio and Copestake, 2003: 6)

${ }^{24}$ As one reviewer pointed out, if into is preceded by a specifier, it can be used as a locative with an extended "fictive path" interpretation (e.g., She was well into the forest now).

${ }^{25}$ Under of can also be found, though probably only in extended (nonspatial) uses, as in: 
(i) The general directive will apply to individuals who fall under of the following criteria: (...) (www)

${ }^{26}$ In this view, out of, too, is a combination of the particle out plus the transitive ancillary preposition of. Traditionally, however, out of is analysed as a complex ("two-word") preposition. See Cappelle (2001) for an overview of some of the arguments for this traditional view, and for an unconventional (and probably illicit) way to treat out in out of as both a particle and a preposition in phrase structure grammar.

${ }^{27}$ Here are some results of a search in Google, carried out on 10 December 2003. In British pages, there were about 29,100 hits for "out of the window" as opposed to about 24,100 hits for "out the window". In pages from the United States, there were about 90,000 hits for "out of the window" but about 400,000 hits for "out the window". By contrast, the combination "out of the box" (where the NP specifies a container, not a landmark) occurred considerably more frequently than "out the box" in both regional varieties (46,200 vs. 2,260 hits in GB pages and 838,000 vs. 17,700 hits in U.S. pages).

${ }^{28}$ The paraphrase 'on the way towards the back of the building' is not completely satisfactory, since it allows the entrance to be somewhere at the beginning of the mental trajectory towards the back of the building, whereas (13c) implies that the entrance is not only in the direction of but also near the back of the building. This may explain why the paraphrase with 'all the way' is not so bad. ${ }^{29}$ When They walked back is combined with an 'in X time' adverbial, several readings can arise: (a) an inchoative reading: They walked back in an hour can be interpreted as 'It lasted an hour before they started to walk back'; (b) an event-related reading (especially if back is preceded by all the way): They walked all the way back in an hour is most likely interpreted as 'It took them an hour to walk all the way back'; (c) a combination of an inchoative and an event-related reading: They [left and] drove back in less than a week can be interpreted as 'Not a week had passed before they were back'. This means that back is more of a path expression than away, since adding an 'in $\mathrm{X}$ time' adverbial to They walked away can only yield an inchoative reading: 'It lasted $\mathrm{X}$ time before they started to walk away'.

${ }^{30}$ It could perhaps be argued that in the grammatical sentence Into the night she sang, the preposed transitive prepositional phrase is nondirectional as well, just like on in On she sang. It is not unreasonable to claim, though, that into the night is only a metaphorical extension from the spatial to the temporal domain, while temporal on is much more distinct from its spatial counterpart, i.e., is not (or no longer) felt to be a metaphorical extension. This is confirmed by the choice of spatial versus temporal modifiers: Deep/further into the night she sang versus on and ever on she sang.

Bert Cappelle was born in 1975. He obtained an MA in linguistics and literature from K.U. Leuven (i.e. the Catholic University of Leuven, Belgium) and is currently writing a doctoral thesis on patterns with particles in English. His supervisor is Renaat Declerck. He has also recently published a couple of book and journal articles on the pragmatic (discourse-functional and affective) meanings of special constructions, such as the particle preposing construction in English and sentence types with the dialogic particle dè in the dialect of his native town Bruges.

Renaat Declerck was born in 1949. He is full Professor of English Linguistics at K.U. Leuven. He has published widely in a large number of journals and has worked on various subjects. He is the author of the following books: Studies on Copular Sentences, Clefts and Pseudo-clefts (Leuven University Press, 1988), Tense in English: Its Structure and Use in Discourse (Routledge, 1991), A Comprehensive Descriptive Grammar of English (Kaitakusha, 1991), When-clauses and Temporal Structure (Routledge, 1997) and Conditionals: A Comprehensive Descriptive Analysis (coauthored by Susan Reed) (Mouton de Gruyter, 2001). 